\title{
Water-Related Research
}

\section{for the Great Lakes Region}

\author{
Report of Efforts to Mobilize \\ Inter-University Water-Related Research \\ in Anticipation of a Great Lakes Megalopolis
}

Spenser W. Havlick and James T. Wilson

The need to mobilize and integrate water-related research efforts in universities of the Great Lakes region is predicated on the growing body of literature documenting the water resources problems of the Great Lakes and the influenced service area that provides goods and services to the people of that region. The gravity of the water pollution problem in localized areas, the fluctuating lake levels, the specter of increasing water treatment costs and decreasing raw water quality for industries and municipalities, the lack of subregional or regional planning guidelines, and the scarcity of high quality water recreation areas all give special emphasis to the need for sophisticated and systematic research directed toward serving human needs.

The difficulty of such a research effort in terms of data collection, regional economic analysis, or organizational innovations that may be required must not be minimized. Models that need to be built will require several years for conceptualization, planning, and implementation.

At the outset we emphasize that water resources research of the Great Lakes region should proceed through an interdisciplinary and rational approach-specifically, 'systems analysis.' Special emphasis must be placed on social values and goals. This discussion outlines various studies that are needed to identify the current research opportunities not only for geophysicists, but economists, political scientists, limnologists, and others. An unprecedented opportunity will be available for research that can be adapted to region-wide operation when financing and technology permit.
As a point of clarification, the term 'Great Lakes region' describes the physiographic, economic, and cultural area which is related more to the Great Lakes than to any other water resource. The 'region' refers to the influenced service area and is not limited to the hydrologic boundaries of the watershed per se. When reference is made to the 'Great Lakes basin' only the hydrologic watershed or 'divide' configuration is intended.

A crisis situation of water pollution or other problems of water management does not hang over the entire Great Lakes region, but it is true that there are localized difficulties of pollution in all of the Great Lakes. Periodically, extremely low or high lake levels create shoreline problems. Hardships are imposed on commercial shippers by fluctuating lake levels and unpredictable ice conditions. In urban areas new shoreline development is contested between recreational, residential, and industrial interests.

At a given site one water use may conflict directly with another. One example is the competition at Niagara Falls for water for hydropower generation as well as for the tourist industry. At present the Niagara River is diverted from the Falls at night for hydropower production and permitted to proceed over the Falls in daytime for the pleasure of visitors.

The need for broad regional planning is illustrated by the fact that not all competing uses of Great Lakes water occur at one site. Chicago, Illinois, is prevented by court action instigated by other Great Lakes states from removing more than $99,050 \mathrm{l} / \mathrm{sec}$ of water for waste disposal dilution and conveyance down the Mississippi River drainage system. States located 
hundreds of miles from Chicago on other Great Lakes, including those affected by Niagara Falls, are concerned about setting a precedent that would be disadvantageous to 'uplake' or 'downlake' states in the future. While this Chicago Sanitary Canal Diversion controversy continues, an average flow of $5,094,0001 / \mathrm{sec}$ moves uncontrolled through the Detroit River to the lower Great Lakes.

There is a long tradition of water-related research on the Great Lakes. In recent years federal legislation has provided increased incentive for university-based water resources research in the form of water resource centers, although appropriations for this research have not kept pace with the needs and crises predicted for the Great Lakes Region.

Planners and water managers with a long-term view have predicted bulges of urban settlement that will meet and overlap from Milwaukee, Wisconsin, to Buffalo, New York, and Toronto, Canada. It is this expectation of a Great Lakes megalopolis that has promoted a renewed interest in what could and should happen to the land and water resources of the midsection of the continent.

Recently the major universities of the Great Lakes region recognized the need to assemble a cadre of investigators to take a hard look at the future development of the region and necessary water-related research activities. Previously this research in the Great Lakes region was approached primarily by several disciplines independently, with little collaboration among universities. Procedures for inter-university cooperation have been proposed as a result of several working conferences held in 1967 and 1968 under a contract to the University of Michigan from the Office of the Water Resources Research of the United States Department of Interior. University investigators who worked in the physical, biological, and social areas of water-related research in the Great Lakes were brought together to determine what research activities for the Great Lakes region should be initiated. One objective of the interuniversity consortium was to prevent research duplication where cooperative ventures appeared to be more effective.

William C. Ackermann, chairman of the inter-university Project Steering Committee, has outlined elsewhere* opportunities for needed research in a regional model. This sort of comprehensive systems analysis model would enable researchers in the various disciplines to see where their work fits into the model and also to see the results they need to make their work compatible with the information required by the model.

The system-wide analysis would also indicate the weakest areas of the model and then allow researchers to give highest priority in these areas. As results are obtained the model could be reformulated and refined to determine the increasing strength in the areas that are further defined and thus keep the areas of greatest effort always before the researchers and those who fund research.

Communications will be opened between researchers in various disciplines since there must be a multidiscipline approach used in developing a comprehensive systems model of the Great Lakes region which will require information exchanges uncommon to a region of this size. Channels of communication will also be opened between concerned individuals

*Analysis of Water and Water-Related Research Requirements in the Great Lakes Region, report prepared by the Council on Economic Growth, Technology and Public Policy of The Committee on Institutional Cooperation, University of Michigan, Ann Arbor, 104 pp., 1968. and groups, inasmuch as it requires the cooperation of data collectors, researchers, and planners to develop the model.

There is need to intensively examine the present status of, and future requirements for, programs of collection, storage, and retrieval of water and water-related data. This examination must lead to a rationalization of water information programs that will fulfill the requirements of research, planning, and management programs in the region.

The examination of data availability and requirements has two particularly important aspects within the systems analysis and modeling framework of any proposed program of research in the Great Lakes region. First there is a need to identify present data-collection sources, the types of data, when collected, and the form in which they are available. This supply of data, when identified, needs to be evaluated as to its adequacy for future research and information program requirements. Second, present and future information needs should be clarified, and proposals for implementing procedures to make these data available and accessible should be outlined, including a review of emerging research and management programs and procedures and the determination of their data requirements. This study should lead to the establishment of strategies for effective dissemination of information to users in private and public planning and policy making activities as well as research activities.

\section{The Water Quality System}

Considerations by the inter-university group of the water quality systems are briefly summarized here as being of principal interest. However, parallel serious deliberation was also given to water quantity models, water-related information systems, a regional economic growth model, and studies of institutions

The modeling of the water quality aspects of the Great Lakes will necessarily take more than one form, because of the complex nature of the numerous elements involved with in the system. It was determined to try two approaches initially, a lake model and a sublake model. The lake-modeling approach is designed to quantify the interrelationship between local areas from a lake-by-lake viewpoint. The sublake approach seeks to describe the nature and alternative courses of action that may take place within a local sector, taking in to account the effect of neighboring sectors. The two approaches are not separate, and the results from the sublake model will allow refinement of the lake model. In fact the two models will be complementary and must be developed simultaneousiy.

The objective of the lake model of the water quality system is to describe the water quality by subregions within each of the lakes of the Great Lakes system. Each subregion will be chosen so as to be relatively homogeneous in its properties, receive local inputs and provide local withdrawal.

Information on the physical nature of lake currents in each lake and the physical, chemical, and biological transformations that accompany the currents in each subregion of the lake, as well as the transfer functions that apply to the exchange of water and material between subregions, must be determined.

The sublake model will complement the lake modeling effort in the water quality system, as well as in the economic growth model. The sublake model indicates the spatial relationships between the local lake sectors and associated water 
uses such as municipal or industrial water supply, cooling water, or recreation. The location, amount, and quality of water put into and withdrawn from each of the subregions must be determined. For some uses it will be possible to employ management or treatment controls on the water quality before or after the water is used; other uses will permit only one or no control measures. After the limits have been established for each water quality parameter, studies must be conducted to determine the types of water and waste treatment methods, management control measures, and enforcement policies that may be employed to control the level of water quality within the limited range for the local sector. The lake model will then integrate these sublake models to determine their interdependence and effect on the entire lake.

A series of studies of the costs and benefits associated with controlling the level of water quality in selected local sectors should be initiated to evaluate the direct costs and benefits that are normally identified, as well as to make professional estimates of those social values that usually escape quantification. Then with the comprehensive assessment of the resources available, the use of demands, ideal and practical institutional and legal constraints, and the interactions of the components of the system, alternative control procedures can be suggested to control and manage the water quality to meet selected social goals.

\section{Summary}

In light of the seriousness of Great Lakes water-related problems, this multidisciplinary, collaborative effort of numerous investigators explored various research methodologies that can be applied in the Great Lakes region.

The major findings from conferences and small group working sessions over a period of six months are briefly listed below:

1. A Great Lakes regional comprehensive model is not feasible at this time. However, subsystem modeling and related water resource research should be developed and supported in each geographic area of the Great Lakes region with the long-range objective of moving toward what is impractical at the time of this writing.

2. Research using systems analysis is needed in water resources management in the Great Lakes region in at least three areas: $(a)$ water quantity and lake level model, $(b)$ water quality model, and $(c)$ economic growth model. Special emphasis is placed on the relative difficulty of each of the proposed models. Past and present efforts were determined to be inadequate in terms of the innovative experimentation expected of university-based researchers.

3. Information retrieval and data storage needs to be co. ordinated for water-related planning operations on a regionwide scale, with cooperation by all public agencies and non. public entities involved.

4. Organizations responsible for water management de. cisions need analysis and evaluation of their effectiveness. Criteria for appraisal and recommendations for (improved) future water resource management must be established with regional parameters paramount in the considerations.

5. Increased data collection and analysis are required in physical, biological, and social areas of Great Lakes water resources research.

6. Universities and other research oriented organizations need a coordinating mechanism for water resources research among themselves and as a linkage to relevant federal and state agencies in the Great Lakes region. The Great Lakes Basin Commission is one possibility.

With guarded optimism, the authors look to the universities of the Great Lakes region which, in conjunction with state and federal agencies, can be mobilized in an effective arrangement to assist planners of the Great Lakes megalopolis. The alternative strategies for action that can be identified and articulated by modeling efforts and supporting research will contribute substantially to the quality of the environment in the region. The problem of inventing viable organizational mechanisms for this or other water-influenced regions presents a challenging opportunity.

Spencer W. Havlick is Assistant Professor of the Department of Resource Planning and Conservation, University of Michigan, and a Faculty Associate of the Institute for Social Research. $\mathrm{He}$ is a Consultant to the Conservation Foundation and the Bureau of Outdoor Recreation. James $T$. Wilson is Director of the Institute of Science and Technology at the University of Michigan. He is a member of the NAS-NRC Committee on Seismology (Chairman 1960-1965), and past member and Chairman of the NAS-NRC Committee on Remote Sensing of Environment. He was a member of the Council on Economic Growth, Technology, and Public Policy of the Committee on Institutional Cooperation and Chairman of their water resources com. mitree. Spencer Havlick served as a staff member on this committee and editor of their report, 'Analysis of Water and WaterRelated Research Requirements in the Great Lakes Region,' which was prepared under contract with the Department of Interior's Office of Water Resource Research.

\section{National Fall Meeting December 15-18, 1969}

